\title{
PHARMACOLOGICAL MANIPULATION OF THE COMPLEMENT SYSTEM IN HUMAN DISEASES.
}

\author{
Syed Shafi Asghar, Ph.D. \\ Division of Biochemistry and Immunology, Department of Dermatology, Academisch Medisch Centrum, University \\ of Amsterdam, Amsterdam, The Netherlands
}

\section{TABLE OF CONTENTS}

1. Introduction

2. The complement system

3. Regulators of complement activation

4. Therapeutic uses of high molecular weight inhibitors of complement 4.1. C1-inhibitor

4.1.1. Treatment of HANE

4.1.2. Control of toxicity caused by $I L-2$ immunotherapy

4.1.3. Treatment of sepsis

4.2. Intravenous immunoglobulin

4.2.1. Autoimmune thrombocytopenic purpura

4.2.2. Kawasaki disease

4.2.3. Myasthenia gravis

4.2.4. Chronic inflammatory demyelinating polyneuropathy

4.2.5. Other diseases

4.3. Factor I, factor $H$ and C4-binding protein $(C 4 B P)$

4.3.1. Factor I deficiency

4.4. Decay accelerating factor (DAF), membrane cofactor protein $(M C P)$ and complement receptor $1(C R 1)$ 4.4.1. DAF

4.4.1.1. Immune complex-induced inflammation

4.4.1.2. Xenotransplantation

4.4.2. $C R I$

4.4.2.1. Reperfusion injury

4.4.2.2. Thermal trauma

4.4.2.3. Hyperacute rejection

4.4.2.4. Immune complex-mediated inflammation

4.4.2.5. Other experimental models

4.4.3. CD59

4.4.3.1. Xenotransplantation

5. Concluding remarks

6. References

\section{INTRODUCTION}

Complement is one of the powerful effector systems involved in the body's defense. When present in a dormant state it can, in concert with other components of immune system, protect the individual from foreign pathogens. However, inappropriately activated complement can cause disease. Several disease states such as immune complex and autoimmune diseases and deficiencies of some

Received 12/08/95; Accepted 01/26/96.

${ }^{1}$ To whom correspondence should be addressed, at Room K2-209, Academisch Medisch Centrum, Meibergdreef 9, 1105 AZ Amsterdam, The Netherlands. Tel\# : 020-5662025. Fax \#: 0205664440 . complement regulators are associated with inappropriate activation of complement. In some diseases complement is activated for a long or indefinite period while in others for a comparatively short time; in some it is activated systemically, in others locally; in some whole cascade is activated, in others only a few components are activated; in some classical pathway is activated, in others alternative pathway. In some diseases activation of complement takes place on cell and tissue surfaces. In many complement activating diseases biological activities of complement fragments become detrimental resulting in tissue injury and disease. Inhibition of complement by specific inhibitors is likely to arrest complement mediated disease processes.

From this point of view, some laboratories are developing low molecular weight synthetic 
inhibitors whereas others are focusing on the development of high molecular weight plasma or cell surface complement inhibitors in their natural or recombinant forms for therapeutic purposes. A review concerning development of low molecular weight inhibitors with the eventual aim of manipulating complement system in human diseases was recently published $(1,2)$. This review is concerned with high molecular weight natural or recombinant complement inhibitory molecules in human plasma or cell membranes, some of which are already in clinical use.

\section{THE COMPLEMENT SYSTEM}

Complement system has recently been reviewed in detail (3-5); only a passing reference of this system will be made here. Activation of complement occurs via classical and alternative pathways. Activation of both pathways serve to covalently opsonize surfaces of foreign invading microorganisms with $\mathrm{C} 3 \mathrm{~b}$ and/or $\mathrm{C} 4 \mathrm{~b}$. $\mathrm{C} 3 \mathrm{~b}$ and $\mathrm{C} 4 \mathrm{~b}$ on foreign cell surfaces serve as the building blocks for the formation of $\mathrm{C} 3 / \mathrm{C} 5$ convertases of classical and alternative pathways. These convertases amplify the initial deposition of $\mathrm{C} 3 \mathrm{~b}$ and catalyze the formation of $\mathrm{C} 5 \mathrm{~b}$ fragment which causes self assembly of C5b-C9 complex, known as membrane attack complex (MAC). This complex causes osmotic lysis of the invading microorganisms. During the activation of both pathways, C3 and C5 breakdown products , $\mathrm{C} 3 \mathrm{a}$ and $\mathrm{C} 5 \mathrm{a}$, are formed. These anaphylatoxins play a role in inflammation; they release histamine from mast cells. These products lead to vasodilation and increased vascular permeability. C5a chemotactically attracts neutrophils. $\mathrm{C} 3 \mathrm{~b}$ and $\mathrm{C} 4 \mathrm{~b}$ on the surface of the opsonized foreign pathogens act as ligands for complement receptors present on phagocytic cells eventually leading to phagocytosis of the pathogens.

\section{REGULATION OF COMPLEMENT ACTIVATION}

The complement system has powerful cytolytic activity against which individual's own cells (self cells) should be protected. Several proteins have evolved to control the extent of complement activation in fluid phase and surfaces of self cells (for recent reviews see 6-9). The proteins which inhibit complement activation in fluid phase serve to limit the generation of complement fragments such as $\mathrm{C} 4 \mathrm{~b}$ and $\mathrm{C} 3 \mathrm{~b}$. They also render the generated fragments inactive thereby reducing the extent of cellular damage. These proteins include $\mathrm{C} 1$-inhibitor (C1INH) $(10,11)$, C4-binding protein (C4BP) (12-14), factor $\mathrm{H}(13-15)$ and factor I $(13,14)$. Some of the fluid phase proteins such as clusterin (16) and vitronectin (17) inhibit the formation of cytolytic MAC. C4b and C3b which have escaped inactivation by fluid phase inhibitors of complement activation and are already fixed to self cells, are inactivated by cell membrane regulators of complement such as decay accelerating factor (DAF) $(7,9,18,19)$, membrane cofactor protein (MCP) $(7,9,20)$ and complement receptor 1 (CR1) $(7,9,21,22)$. Some of the cell membrane proteins, CD59 (7,23-25) and homologous restriction factor (HRF) $(7,26)$, render MAC non-cytolytic while it is being formed on the self cell. Thus, fluid phase inhibitors in conjunction with membrane embedded inhibitors protect cells from autologous complement. The individual functions of these fluid phase and cell surface complement regulatory proteins are summarized in Table 1.

\section{THERAPEUTIC USES OF HIGH MOLECULAR WEIGHT INHIBITORS OF COMPLEMENT}

\subsection{C1-Inhibitor (C1-INH)}

C1-inhibitor has recently been reviewed $(10,11)$. It interacts with the activated $\mathrm{C} 1$. Interaction of $\mathrm{C} 1-\mathrm{INH}$ with activated $\mathrm{C} 1$ complex leads to the dissociation of $\mathrm{C} 1 \mathrm{q}$ subunit and formation of $\mathrm{C} 1 \mathrm{r}$ $\mathrm{C} 1 \mathrm{~s}-(\mathrm{C} 1-\mathrm{INH})_{2}$ complex. Inhibition of $\mathrm{C} 1 \mathrm{r}$ and $\mathrm{C} 1 \mathrm{~s}$ results in the inhibition of cleavage of $\mathrm{C} 4$ and $\mathrm{C} 2$ by the activated $\mathrm{C} 1 \mathrm{~s}$. The inhibition of $\mathrm{C} 1$ by $\mathrm{C} 1-\mathrm{INH}$ is about 100 times more effective in fluid phase than on the cell surface (27). Thus $\mathrm{C} 1$ activated in a fluid phase can be inhibited much more easily than the $\mathrm{C} 1$ activated on the target cell surface.

The regulation of complement at $\mathrm{C} 1$ stage is abrogated in patients with genetic deficiency of $\mathrm{C} 1$ INH (hereditary angioneurotic edema; HANE), patients with cancer undergoing treatment with IL-2 and septic patients. C1-INH is beneficial in these situations.

\subsubsection{Treatment of hereditary angioneurotic edema (HANE) \\ HANE has recently been reviewed $(10,11)$.} In this disease, occasional bouts of acute edema occur in extremities, gastrointestinal tract or orificial areas. Approximately $85 \%$ of the patients have type I HANE in which C1-INH structure and function is normal but its plasma levels are low (5-30\% of normal) and about $15 \%$ have type II HANE in which C1-INH protein is structurally and functionally abnormal but its plasma levels remain normal or even elevated. Anxiety or trauma can precipitate attacks of edema in these patients. The mechanism of attack of edema has not yet been firmly established. It is believed that any event that can cause local depletion of C1-INH in HANE can cause local activation of $\mathrm{C} 1$ in fluid phase. Local depletion of C1-INH in HANE can easily occur due to low levels of this inhibitor. Activated $\mathrm{C} 1$ can then cleave $\mathrm{C} 4$ and $\mathrm{C} 2$. C2 fragment is further cleaved by plasmin to a small vasoactive peptide, $\mathrm{C} 2$ - 
Clusterin

Vitronectin

Cell membrane regulators

1. C3/C5-convertase

formation stage

DAF

MCP

CR1

2. MAC formation stage

CD59

$\mathrm{HRF}$
Prevents the assembly of cytolytic MAC

Prevents the assembly of cytolytic MAC
16

17 $\begin{array}{ll}\text { Dissociates C2a and Bb from C4b and C3b } & 7,9,18,19 \\ \begin{array}{l}\text { Cofactor for factor I in cleaving C4b/C3b } \\ \text { Cofactor for factor I in cleaving C4b/C3b and }\end{array} & 7,9,20 \\ \text { decay acceleration of C3/C5-convertases } & 7,9,21,22 \\ & \\ \text { Inhibits formation of cytolytic MAC on self cell } & 7,23-25 \\ \text { Inhibits formation of cytolytic MAC on self cell } & 7,26\end{array}$

* for unabbreviated names see the text.

kinin. This kinin is thought to be responsible for the attack of edema in HANE.

C1-INH prepared from normal plasma in concentrated form is used as short term replacement therapy for the treatment of attacks of HANE $(10,11)$. This therapy is life saving in laryngeal edema. Surgery can precipitate attack of edema which under certain circumstances can be life threatening. Surgery can, however, be safely performed on these patients if they are pre-treated with high doses of C1-INH and thus have acquired normal functional levels of $\mathrm{C} 1$ INH (28). Since the discovery that in HANE patients attenuated androgens can increase plasma C1-INH levels to normal in few days, attenuated androgens such as danazol are used on long term basis to prevent attack of edema (1,29).

\subsubsection{Control of toxicity caused by Interleukin-2 (IL-2) Immunotherapy}

C1-INH treatment is beneficial in patients undergoing IL-2 therapy. IL-2 treatment can induce partial or complete remission in advanced melanoma and renal carcinoma (30) but its use has been limited due to its toxicity. IL-2 treatment causes a life threatening vascular leakage syndrome characterized by hypotension and other changes similar to those seen in septic shock. During IL-2 therapy, complement (via classical pathway) as well as contact system are activated. Both these systems are regulated by $\mathrm{C} 1-\mathrm{INH}$. Vascular leakage syndrome is associated with the activation of complement. In a pilot study on six patients with metastatic melanoma and renal cell carcinoma receiving high doses of IL-2, C1-INH treatment resulted in inhibition of complement activation. The authors concluded that C1-INH therapy leads to reduced IL-2 toxicity. This pilot study warrants further investigations on the ability of C1-INH alone or in combination with any of the inhibitors of complement described below to reduce IL-2 induced toxicity.

\subsubsection{Treatment of sepsis}

Complement and contact systems are activated by microorganisms and inhibited by high doses of C1-inhibitor. In an experimental model of endotoxic shock in dogs one group received Escherichia coli (E coli) endotoxin and the other C1INH before $E$ coli endotoxin was administered. In the latter group of animals, C1-INH prevented endotoxininduced pulmonary dysfunction namely hypoxemia (30). High doses of C1-INH have been safely administered to patients with septic shock in whom C1-INH turnover is increased. C1-INH reduced such complications as activation of complement and contact system and hypotension. It reduced mortality in pilot studies (31). Further studies are needed to establish whether $\mathrm{C} 1-\mathrm{INH}$ can reduce mortality and morbidity in septic patients. 


\subsection{Intravenous Immunoglobulin}

Intravenous immunoglobulin is prepared from plasma of a large number of healthy donors (for recent reviews see 32-34). This product consists of 95\% IgG in same proportion of its subclasses as in plasma. Depending on the number of donors from whom plasma pool has been prepared, intravenous immunoglobulin contains variable amounts of $\mathrm{IgG}$ dimers. The higher the number of donors, the higher the content of such dimers. Intravenous immunoglobulin prepared from a large plasma pool (100,000 donations) may contain up to $30-40 \%$ dimers. These dimers are made up of idiotype (Id) IgG molecules and a complementary anti-Id antibody (35). Commercially available intravenous immunoglobulins are prepared by different methods, contain different additives, vary in $\mathrm{pH}$ (4-6), and may contain IgA.

Intravenous immunoglobulin exhibits a number of immunomodulating properties (32-34). Since it is prepared from the plasma of a large number of donors, it contains antibodies directed against a variety of antigens, self antigens (natural autoantibodies) and self antibodies (anti-idiotypic antibodies). In vivo, it inhibits B-cell activation and autoantibody production, neutralizes circulating pathogenic antibodies and suppresses antibodydependent cellular cytotoxicity (ADCC) by FcgR blockade. In vitro, it inhibits pokeweed mitogenstimulated antibody production, neutralizes multiple autoantibodies through its antiidiotype reservoir and exhibits pronounced effects on T-cell mediated immunity (36,37). It enhances CD8 positive suppressor T-cell function in vivo and in vitro (36), and reversibly inhibits proliferation of antigen specific as well as antigen independent stimulation of lymphocytes (37). Intravenous immunoglobulin also inhibits the proliferation of a wide variety of hybridomas and cell lines. Further experiments showed that it arrested the cell cycle in G0-/G1phase; inhibiting progression into S-phase (36). Intravenous immunoglobulin also inhibits the activation and function of NK cells (38) and interferes with the cytokine network by inhibiting the release of cytokines (39). It contains autoantibodies that react with some cytokines such as IL-1 leading to the neutralization of their activities (40). In addition, intravenous immunoglobulin can upregulate IL-1 receptor antagonist (41). It can also inhibit the complement system; it inhibits complement activation at C1 stage (42) and at the stage of binding of complement fragments ( $\mathrm{C} 3 \mathrm{~b}$ and $\mathrm{C} 4 \mathrm{~b})$ to target cells (43). It is not currently known whether besides these inhibitory activities, intravenous immunoglobulin exerts similar activities at other sites of complement cascade. Besides its use in replacement therapy in primary immunodeficiencies, it has been found to be beneficial in more than 30 immunological diseases (32-34). The mechanisms for the beneficial effects of intravenous immunoglobulin in these diseases are currently unknown. Although the role of inhibition of complement as the basis for the beneficial effects of intravenous immunoglobulin has not been established as yet, it is interesting to note that most diseases in which it exerts beneficial effects are complementmediated.

Some of the diseases in which efficacy of intravenous immunoglobulin has been tested in a relatively large number of patients and has been firmly established are described below.

\subsubsection{Autoimmune thrombocytopenic purpura (ITP)}

Administration of intravenous immunoglobulin is efficacious in acute ITP in children and is considered treatment of choice (for recent review see 33,44). In adults with acute ITP, treatment with intravenous immunoglobulin is likely to produce long term remission during the first six months rather than latter. In children and adults with ITP, autoantibodies to platelet glycoproteins IIb/IIa and Ib/IX are present in plasma and on platelets. Platelet counts in these patients is very low but following intravenous immunoglobulin treatment $(400 \mathrm{mg} / \mathrm{kg} / \mathrm{day})$ it rises to approximately $30 \times 10^{9}$ per liter within 48 hours of the therapy $(33,45,46)$. If platelet count is not significantly increased during this time, additional dose is given daily for five days.

Following treatment with intravenous immunoglobulin, about $62 \%$ of children with chronic ITP undergo long term remissions. In adults with chronic ITP the response rate is lower. However, in the majority of patients a substantial but short term increase in platelet count is observed $(33,45,46)$.

An idiotypic mechanism and blockade of FcR on reticuloendothelial cells may be the main mechanism of action of intravenous immunoglobulin in ITP $(33,44)$. In short term, inhibition of complement and in long term, decrease in antiplatelet antibody production are likely to be the mechanisms by which intravenous immunoglobulin protects platelets from destruction.

\subsubsection{Kawasaki disease}

Kawasaki disease is a leading cause of acquired heart disease in children. This disease is characterized by rash, edema and erythema of hands and feet and aneurysms of coronary arteries. Intravenous immunoglobulin therapy reduces early inflammatory symptoms and decreases the incidence of coronary abnormalities in this disease (for recent reviews see 33,47-49). It has been suggested that activation of complement in this disease is mediated by bacterial toxins which results in the release of cytokines in a manner reminiscent to that seen in toxic shock syndrome $(33,49,50)$. It has been shown that intravenous immunoglobulin neutralizes these toxins and their effects $(33,49,50)$. Intravenous 
immunoglobulin suppresses T- and B- cell activation and excessive production of cytokines such as IL-1, IL-6, TNF and T-cell cytokines (probably caused by C activation), that appear during acute phase of vasculitis in Kawasaki disease. Immediate resolution of fever by intravenous immunoglobulin therapy could be due to its ability to neutralize IL-1 and IL-6. Coronary artery damage in Kawasaki disease appears to be mediated by autoantibodies to endothelial cells. These antibodies induce complement mediated injury to cytokine-stimulated endothelial cells. Intravenous immunoglobulin can perhaps inhibit the production and reactivities of these antibodies by an idiotypic mechanism. During the first ten days of the disease, intravenous immunoglobulin $(400 \mathrm{mg} / \mathrm{kg} /$ day for five days) in conjunction with aspirin is the standard method of treatment for the prevention of the development of aneurysms of coronary arteries.

\subsubsection{Myasthenia gravis}

In myasthenia gravis, autoantibodies to acetylcholine receptor (AChR) are present in circulation and at the neuromuscular junction. Intravenous immunoglobulin $(400 \mathrm{mg} / \mathrm{kg} /$ day for 5 days) results in clinical improvement in a majority of the patients within 24 hours to three weeks (for recent reviews see $33,51,52$ ). The improvement is associated with a decrease in the levels of anti-AChR antibodies. These effects last for 40-49 days. It is currently not known as to how much of the clinical improvement is due to inhibition of complement. Treatment with intravenous immunoglobulin allows a reduction in the dose of corticosteroids and immunosuppressive drugs and reduces symptoms during the time required for these therapies to be effective.

\subsubsection{Chronic inflammatory demyelinating polyneuropathy (CIDP)}

CIPD is a chronic form of Guillian Barré Syndrome. Patients with CIPD have antibodies reactive with myelin, Schwann cells and other nerve structures. These antibodies can activate complement. Intravenous immunoglobulin therapy $(400 \mathrm{mg} / \mathrm{kg} / \mathrm{day}$ for five days; treatment is repeated if necessary) has been shown to be beneficial in this disease $(33,53)$. A vast majority of these patients make a satisfactory recovery within six months of treatment.

\subsubsection{Other diseases}

In small groups of patients the role of intravenous immunoglobulin in the treatment of many diseases has been tested and found to have beneficial effects. For example, the results of different pilot studies have shown that intravenous immunoglobulin prevents complement-mediated destruction of fetal allografts in recurrent spontaneous abortions (for a recent review see 54). In a study, five women who among them had twenty three abortions were given $500 \mathrm{mg}$ intravenous immunoglobulin per month starting before conception. Four gave birth to healthy infants and fifth was at twelve weeks of gestation (55).

Some of the diseases in which effects of intravenous immunoglobulin therapy have been tested in small groups of patients and found to have beneficial effects are listed in Table II. Since different workers have used different regimens of treatment in these diseases, in some cases in combination with other treatments, readers may refer to the original articles for methods of treatment.

\subsection{Factor I, Factor H And C4-Binding Protein (C4BP)}

A complement inhibitor is likely to be effective in complement-mediated diseases if it inhibits activation of complement before or at the stage of formation of $\mathrm{C} 3 / \mathrm{C} 5$ convertase. This inhibition suppresses damage of self cell and C5ainduced recruitment of neutrophils and inflammation. Factor $\mathrm{H}$ and $\mathrm{C} 4 \mathrm{BP}$ are far much less potent than the recombinant soluble CR1 (see below) in inhibiting classical and alternative pathways, thus, they have not been used in the treatment of complement-mediated diseases. Nevertheless, Factor I, Factor H and C4BP are likely to be effective in substitution therapy in patients with their deficiencies. Factor I has been used in the treatment of Factor I deficiency as described below. Although recombinant factor $\mathrm{H}$ has been produced (58), neither natural nor recombinant factor $\mathrm{H}$ has been tried in factor $\mathrm{H}$ deficiency (14). C4BP has also not yet been tried in the replacement therapy in C4BP deficiency (59).

\subsubsection{Factor I deficiency}

Several patients who suffer from factor I deficiency have been diagnosed (14,60). In this deficiency regulation of $\mathrm{C} 3 / \mathrm{C} 5$-convertase of alternative pathway is impaired. These patients have very low plasma levels of native $\mathrm{C} 3$ and factor $\mathrm{B}$. The underlying basis for this low plasma level of $\mathrm{C} 3$ and factor $\mathrm{B}$ seems to be increased generation of $\mathrm{C} 3 \mathrm{bBb}$ complex whose decay is reduced due to factor I deficiency. Circulating $\mathrm{C} 3 \mathrm{bBb}$ generates high levels of $\mathrm{C} 3 \mathrm{~b}$ which in turn leads to the generation of more $\mathrm{C} 3 \mathrm{bBb}$ complex. Free $\mathrm{C} 3 \mathrm{~b}$ or $\mathrm{C} 3 \mathrm{~b}$ in this complex is not converted to $\mathrm{C} 3 \mathrm{bi}$ or $\mathrm{C} 3 \mathrm{~d}$. Administration of factor I to one of the patients with factor I deficiency normalized C3b levels within few hours (61).

Normalization of the native C3, C5 and classical pathway activities, however, took about four days and these activities remained normal for an additional one week (61). Factor B and properdin levels and opsonic and bactericidal activities normalized within 24 hours and stayed normal for the subsequent five days in this patient (61).

4.4. Decay Accelerating Factor (Daf), Membrane Cofactor Protein (Mcp) And Complement Receptor 1 (CR1)

Soluble forms of DAF (62), MCP (63) and 
Table II. Examples of diseases in which beneficial effects of intravenous immunoglobulin has been demonstrated in a small group of patients.

\begin{tabular}{ll}
\hline Disease & References \\
\hline 1. Anemias of different types & $32-34$ \\
2. Neutropeneas of different types & $32-34$ \\
3. Multiple sclerosis & $32-34$ \\
4. Systemic lupus erythematosus & $32-34$ \\
5. Polymyositis and Sjogrens syndrome & $32-34$ \\
6. Rheumatoid arthritis & $32-34$ \\
7. Insulin dependent diabetes & $32-34$ \\
8. Pyoderma gangrenosum & $32-34,56$ \\
9. Bullous pemphigoid & $32-34$ \\
10. Thyroid related eye disease & $32-34$ \\
11. Uveitis & $32-34$ \\
12. Asthma in children & $32-34$ \\
13. Crohn's disease/ ulcerative colitis & $32-34$ \\
14. Recurrent abortions & $32-34$ \\
15. Epidermolysis bullosa acquisita & $32-34,57$
\end{tabular}

CR1 (64) in body fluids regulate activation of complement in the fluid phase. Recombinant soluble forms of human DAF (65), MCP (66) and CR1 (67) inhibit activation of complement in vitro. Soluble forms of recombinant DAF and CR1 were tested and found to suppress complement-mediated disease processes in experimental animals $(65,67)$. Therapeutic uses of recombinant forms of these inhibitors of complement have recently been reviewed (68).

\subsubsection{Decay Accelerating Factor (DAF)}

Moran et al. engineered and extracted three types of recombinant human DAF (65). These include glycosyl phosphatidyl inositol (GPI) moiety-bearing membrane DAF (mDAF), soluble DAF (sDAF) analogous to soluble DAF found in urine and a secretary form of DAF (seDAF) which lacked GPIanchor for attachment to cell membrane. mDAF by virtue of having GPI-anchor could be incorporated into cell membranes and as compared with SDAF or seDAF was found to be a more potent inhibitor of complement on cell surfaces. In contrast, activation of complement in the fluid phase was inhibited by SDAF and seDAF but not by mDAF. seDAF inhibited $\mathrm{CP}$ and AP mediated generation of C5a (65).

\subsubsection{Immune complex-induced inflammation} seDAF inhibited reverse passive Arthus reaction in guinea pigs suggesting that it inhibits immune complex-mediated inflammation (65). In spite of the fact that human DAF inhibits human complement much more effectively than guinea pig complement, human seDAF significantly slowed the development of reverse passive Arthus reaction vasculitis in guinea pigs. For $60-80 \%$ suppression of vasculitis, the effective dose of seDAF was in the range of $75-150 \mathrm{mg} / \mathrm{site}$ which was more than 200 times the effective dose of sCR1 (see below) probably because of species specificity of DAF (65). However, seDAF is likely to be much more effective in complement-mediated human diseases on a dose basis since it inhibits human complement more strongly.

\subsubsection{Xenotransplantation}

Because of the shortage of human organs available for transplantation, relentless efforts are invested to transplant animal organs (xenografts) to humans (for recent review see 69). Complement plays a major role in hyperacute rejection of xenograft (for recent reviews see 70,71). In most animal species combinations classical pathway but in some alternative pathway mediates hyperacute rejection (71). Resistance endowed upon animal cells by incorporation or transfection of these cells with human complement regulatory molecules provide hope that organs of transgenic animals expressing human complement regulatory proteins in the endothelial and other cells of various organs may allow successful transplantation of animal organs to humans. Since it is believed that pig organs are most suitable for human transplantation, pigs transgenic for human complement regulatory proteins are being produced (72). Discussion on other animals transgenic for these molecules will be avoided here.

Transplantation of vascularized organs on discordant animals results in hyperacute rejection of the organ, in part, due to presence of naturally occurring antibodies. In pig-to-human transplantation, the majority of human antibodies react with gal(alpha 1-3)-gal epitopes of integrins on the endothelial cells of the donor pig organ. Antibodies and complement mediate a hyperacute rejection 
within minutes to hours $(69,71)$. This results in severe endothelial cell injury and the loss of natural anticoagulant surface which in turn leads to local and generalized intravascular coagulation. Since membrane regulators of complement are homologously restricted, pig MCP, DAF, CD59 and HRF present on the endothelium of pig organs can not efficiently prevent activation of human complement or effectively influence hyperacute rejection of transplanted pig organs in humans. It has therefore been suggested that the organs of pigs transgenically altered to express human membrane regulatory molecules in endothelial and other cells may be useful for transplantation to humans. Transgenic pigs have been produced that express amounts of human DAF in their organs (heart, liver, pancreas and muscle) that are comparable to that found in human tissues $(73,74)$. These amounts were several fold more in homozygous than heterozygous transgenic pigs. Only expression in the lung was less than that seen in human lung. Expression of the protein in endothelial cells was greater than that seen in human umbilical cord vascular endothelial cells (74). The fact that the endothelial cells from such transgenic pigs were not susceptible to lysis by human complement provides hope for use of organs from these animals in xenotransplantation.

\subsubsection{Complement Receptor-1 (CR1)}

Soluble form of recombinant CR1 (sCR1) was produced by introducing a stop codon in CR1 cDNA before the transmembrane domain (67). sCR1 bound $\mathrm{C} 3 \mathrm{~b}$ and $\mathrm{C} 4 \mathrm{~b}$ in fluid phase and acted as a cofactor for the enzyme factor I in the cleavage of $\mathrm{C} 3 \mathrm{~b}$ and C4b $(67,68)$. Hemolytic activities of classical and alternative pathways and generation of $\mathrm{C} 3 \mathrm{a}$ and $\mathrm{C} 5 \mathrm{a}$ were both inhibited by $\mathrm{sCR} 1$ at a very low concentration.

Since CR1 is not species specific, sCR1 could be tested in several animal models of Cmediated human diseases.

\subsubsection{Reperfusion injury}

Reperfusion of ischemic tissue causes tissue injury more than that caused by ischemia alone. Ischemia/reperfusion injury is mediated by complement (for recent review see 75). The major mechanisms responsible for the injury include C5adependent recruitment of neutrophils; their adherence to the site of $\mathrm{C} 3 \mathrm{~b}$ deposition on the endothelium via C3-receptors and formation of MAC. In myocardial ischemia/reperfusion injury in rats (76), sCR1 reduced the size of the infarct by approximately half. Protective effect of sCR1 was due to inhibition of complement deposition including formation of MAC, accumulation of neutrophils on endothelial cells in the ischemic zone, complement-mediated neutrophil activation, generation of free radicals and contractility failure in post-ischemic heart. Reperfusion injury to ischemic smooth muscle and mucosa of the guts in rats was also inhibited by SCR1 due to inhibition of activation of complement and neutrophil accumulation (77). Skeletal muscle ischemia and reperfusion injury, as might occur in trauma and vascular occlusion was also inhibited by sCR1 (78). In cremaster muscle ischemia and reperfusion model in the mouse, leukocyte recruitment and their vascular adherence was reduced and muscle viability was improved by treatment with SCR1 (79).

\subsubsection{Thermal trauma}

Burn injury is known to cause activation of complement (80) which presumably leads to further injury in the host. Consistent with this hypothesis, in an experimental model of thermal injury, sCR1 not only reduced dermal but also pulmonary vascular permeability and hemorrhage (81).

\subsubsection{Hyperacute rejection}

sCR1 prolonged the survival of porcine cardiac xenografts perfused with human blood (82). Beside this model, dose dependent prolongation of xenograft survival has been seen in several other animal models $(83,84)$.

\subsubsection{Immune complex-mediated inflammation} sCR1 inhibited the immune complexmediated inflammation in reverse passive Arthus reaction in rats (67). Dermal administration of sCR1 in a dose dependent manner reduced deposition of $\mathrm{C} 3$ and C5-C9 (C9 neoantigen) and the extent of reverse passive Arthus reaction vasculitis (67). The concentration of human sCR1 required to suppress deposition of complement and vasculitis in rats $(0.3$ $\mathrm{mg} / \mathrm{site}$ ) was far lower than the effective concentration of human seDAF needed to inhibit reverse passive Arthus reaction in guinea pigs probably because $\mathrm{SCR} 1$ is not species-specific.

\subsubsection{Other experimental models}

Treatment with sCR1 has produced promising results in experimental models of many Cmediated diseases including experimental alveolitis, allergic encephalomyelitis and glomerulonephritis (for recent reviews see $68,85,86$ ). According to the studies carried out so far it appears that human sCR1 is not antigenic in humans and thus is safe for therapeutic purposes. sCR1 is being tested in clinical trials in ARDS and in myocardial infarction $(85,86)$. These and other studies may establish the role of sCR1 in the treatment of many complement-mediated human diseases.

\subsubsection{CD59}

\subsubsection{Inhibition of hyperacute rejection phase of Xenotransplantation}

Fodor et al. (87) have produced transgenic pigs which express in their organs high levels of human CD59 on a variety of cells including endothelium of large vessels and capillaries. These 
cells were significantly resistant to a high titer of anti-porcine antibodies and human complement. Since organs of pigs transgenic for human DAF (see above) or CD59 exhibit a higher resistance to human complement than those of non-transgenic pigs, it is highly desirable to produce pigs transgenic for multiple human complementary regulatory molecules, including DAF, MCP, CD59, HRF and CR1. Efforts are being made to identify promotors that provide higher level of expression of these molecules in endothelial cells. The organs of pigs transgenic for multiple regulators of complement with a high degree of expression of all the regulators may perhaps find their way in organ transplantation.

\section{CONCLUDING REMARKS}

High molecular weight natural inhibitors of complement have found clinical use in many diseases but may also prove useful in other complementmediated diseases. The most promising of these are C1-INH, intravenous immunoglobulin and sCR1. These appear to be non-toxic and non-immunogenic. Complete inhibition of complement by these molecules appears to have little effect, if any, on susceptibility to infection.

In addition to these molecules, membrane inhibitors of complement may also find their way into the clinic. It is hoped that in future, organs of transgenic pigs expressing high levels of multiple human membrane regulators of complement may prove to be useful for transplantation into humans. It is apparent from this review that it is possible to control complement mediated human diseases by use of high molecular weight complement inhibitors of human origin.

\section{REFERENCES}

1. S.S. Asghar: Pharmacological manipulation of the complement system. Pharm Rev 36, 223-44 (1984)

2. S.S. Asghar: Pharmacological manipulation of complement in dermatology. In: Skin Immune System (ed. J.D. Bos). 2nd edition. CRC Press, Inc. Boca Raton, Florida. 1996; in press.

3. M.K. Liszewiski \& J.P. Atkinson. The complement system. In: Fundamental Immunology (ed. W.A. Paul). Raven press. New York. 1993; 917-39

4. S.S. Asghar: Complement in physiopathology of skin. In: Skin Immune system (ed. J.D.Bos). CRC Press, Inc. Boca Raton, Florida. 1990; 207-41

5. H.J. Muller-Eberhard: Molecular organization and function of the complement system. Ann Rev Biochem 57, 321-47 (1988)
6. S.S. Asghar: Complement and complement regulatory proteins. In: Skin Immune system (ed. J.D.Bos). CRC Press, Inc. Boca Raton, Florida. 1996; in press.

7. S.S. Asghar: Membrane regulators of complement activation and their aberrant expression in disease. Lab Invest 72, 254-71 (1995)

8. B.P. Morgan \& S. Meri: Membrane proteins that protect against complement lysis. Springer Semin Immunopathol 15, 369-96 (1994)

9. D. Hourcade, V.M. Holers, J.P. Atkinson: The regulators of complement activation (RCA) gene cluster. Adv Immunol 45, 381-416 (1989)

10. Z.N. Oltvai, E.C.C. Wong, J.P. Atkinson, K.S.K. Tung: C1-inhibitor deficiency: Molecular and Immunological basis of hereditary and acquired angioedema. Lab Invest 65, 381-8 (1991)

11. A.E. Davis III: C1 Inhibitor and hereditary angioneurotic edema. Ann Rev Immunol 6, 595-628 (1988)

12. M. Hessing: The interaction between complement C4b-binding protein and the vitamin $\mathrm{K}$ dependent protein $\mathrm{S}$ forms a link between blood coagulation and complement system. Biochem J 227, 581-92 (1991)

13. R.D. Campbell, S.K.A. Law, K.B.M. Reid, R.B. Sim: Structure, organization and regulation of the complement genes. Ann Rev Immunol 6, 161-95 (1988)

14. R.B. Sim, K. Colbe, M.A. Mc Aleer, O. Doninguez \& V.M. Dee: Genetics and deficiencies of soluble regulatory proteins of the complement system. Int Rev Immunol 10, 65-86 (1993)

15. P.F. Zipfel \& C. Skerka: Complement factor H and related proteins: an expanding family of complement-regulatory proteins? Immunology Today 15, 121-6 (1994)

16. D.E. Jenne \& J. Tschopp: Clusterin: the intriguing guises of a widely expressed glycoprotein. Trends Biochem Sci 17, 154-9 (1992)

17. K.T. Preissner: Structure and biological role of vitronectin. Ann Rev Cell Biol 7, 275-310 (1991)

18. D.M. Lubin \& J.P. Atkinson: Decay-accelerating factor: Biochemistry, molecular biology, and function. Ann Rev Immunol 7, 35-58 (1989)

19. A. Nicolson-Weller: Decay accelerating factor (CD55). Curr Top Microbiol Immunol 178, 7-30 (1992) 
20. M.K. Liszewski, T.W. Post \& J.P. Atkinson: Membrane cofactor protein (MCP or CD46): Newest member of the regulators of complement activation gene cluster. Ann Rev Immunol 9, 431-55 (1991)

21. J.M. Ahearn \& D.T. Fearon: Structure and function of the complement receptor CR1 (CD35) and CR2 (CD21). Adv Immunol 46, 183-219 (1989)

22. W.W. Wong: Structural and functional correlation of the human complement receptor type 1. J Invest Dermatol 94 (suppl), 64-67 S (1990)

23. G.T. Venneker \& S.S. Asghar: CD59: A molecule involved in antigen presentation as well as down regulation of membrane attack complex. Exp Clin Immunogen 9, 33-47 (1992)

24. L.A. Walsh, M. Tone, S. Thiru, H. Waldmann: CD59 antigen - a multifunctional molecule. Tissue antigens 40, 213-220 (1992)

25. A. Davies \& P.J. Lachman: Membrane defense against complement lysis: The structure and biological properties of CD59. Immunol Res 12, 25875 (1993)

26. L.S. Zalman: Homologous restriction factor. Curr Topics Microbiol Immunol 178, 87-99 (1992)

27. A.J. Tenner \& M.M Frank: Activator bound $\mathrm{C} 1$ is less susceptible to inactivation by $\mathrm{C} 1$ inhibitor than is fluid phase C1. J Immunol 137: 625-30 (1986)

28. A. Leimgruber, W.A. Jaques \& P.J. Spaeth: Hereditary angioedema- Uncomplicated Maxillofacial surgery using short term C1-inhibitor replacement therapy. Int Arch Allergy Immunol 101, 107-12 (1993)

29. J. Gadek, S.W. Hosea, J.A. Gelfand \& M.M. Frank: Response of variant hereditary angioneurotic edema phenotypes to danazol therapy. Genetic implications. J Clin Invest 64, 280-6 (1979)

30. R. Guerrero, F. Velasco, M. Rodriguez, A. Lopez, R. Rojas, M.A. Alvarez, R. Villalba, V. Rubio, A. Torres \& D. del Castillo: Endotoxin-induced pulmonary dysfunction is prevented by $\mathrm{C} 1$-esterase inhibitor. J. Clin Invest 91, 2754-60 (1993)

31. C.E. Hack, A.C. Ogilia, B. Eisele, P.M. Jansen, J. Wagstaff \& L.G Thijs: Initial studies on administration of C1-esterase inhibitor to patients with septic shock or with a vascular leakage syndrome induced by interleukin-2 therapy. Progr Clin Biol Research 388, 335-57 (1994)
32. R.I. Schiff: Intravenous gammaglobulin: pharmacology, clinical uses and mechanism of action. Pediatr Allergy Immunol 5, 63-7 (1994)

33. J.M. Dwyer: Manipulating the immune system with immune globulins. New Engl J Med 326, 107-16 (1992)

34. V.R. De Souza, S.V. Kaveri \& M.D. Kazatchkine: Intravenous Immunoglobulin (IVIG) in the treatment of autoimmune and inflammatory diseases. Clin Exp Rheumatol 11 (Suppl), S 33-6 (1993)

35. K.E. Roux \& D.L. Tankersley: A view of the human idiotypic repertoire. Electron microscopic and immunologic analyses of spontaneous idiotype-antiidiotype dimers in pooled human IgG. J Immunol $144,1387-95$ (1990)

36. M.G. Macey \& A.C. Newland: CD4 and CD8 subpopulation changes during high dose intravenous immunoglobulin treatment. Br J Hematol 76, 513-20 (1990)

37. I.N. van Schaik, I. Lundkvist, M. Vermeulen \& A. Brand: Ployvalent immunoglobulin for intravenous use interferes with cell proliferation in vitro. J Clin Immunol 12, 1-10 (1992)

38. D.Engelhard, J.L. Waner, N.Kapoor \& R.A.Good: Effect of intravenous immunoglobulin on natural killer cell activity: possible association with autoimmune neutropenia and idiopathic thrombocytopenia. J Pediatr 108, 77-81 (1986)

39. T. Shimozato, M. Iwata, H. Kawada \& N. Tamura: Human immunoglobulin preparation for intravenous use induces elevation of cellular cyclic adenosine 3':5'-monophosphate levels, resulting in suppression of tumor necrosis factor alpha and interleukin-1 production. Immunology 72, 497-501 (1991)

40. J.A. Schifferli, L. Didierjean \& J.H. Saurat: Immunomodulatory effects of intravenous immunoglobulin G. J Rheumatol 18, 937-9 (1991)

41. W.P. Arend, M.F. Smith, R.W.Janson \& F.G. Joslin: IL-1 receptor antagonist and IL-1 beta production in human monocytes are regulated differently. J Immunol 147,1530-6 (1991)

42. M. Qi \& J.A.Schifferli: Inhibition of complement activation by intravenous immunoglobulins. Arthritis Rheum 38, 146 (1995)

43. M. Basta, L.F. Fries \& M.M. Frank: High doses of intravenous Ig inhibit in vitro uptake of $\mathrm{C} 4$ fragments onto sensitized erythrocytes. Blood 77 , 376-80 (1991) 
44. P. Berchtold P \& R. Mc Millen: Intravenous immunoglobulin: new aspects of mechanism of action in chronic ITP. In: Immunotherapy with Intravenous Immunoglobulins (ed. P. Imbach), Academic Press, London. 1991; 245-52

45. J.M. Lusher \& I. Warrier: Use of intravenous immunoglobulin in children and adolescents with idiopathic thrombocytopenic purpura and other immune thrombocytopenias. Am J Med 4 (Suppl A), 10-6 (1987)

46. J.P. Bussel. The use of intravenous-g-globulin in idiopathic thrombocytopenic purpura. Clin Immunol Immunopathol 53, S 147-55 (1989)

47. S.T. Shulman: Kawasaki disease and IVIG: what is going on here ? In: Immunotherapy with Intravenous Immunoglobulins (ed. P. Imbach). Academic Press, London. 1991; 261-8

48. J.W. Newburger, M. Takahashi, J.C. Burns, A.S. Beiser, K.J. Chung, C.E. Duffy, M.P. Golde, W.H. Mason, V. Reddy, S.P. Sanders, S.T. Shulman, J.W. Wiggins, R.W. Hicks, D.R. Fulton, A.B. Lewis, D.Y.M. Leung, T. Colton, F.S. Rosen \& M.E. Malish: The treatment of Kawasaki syndrome with intravenous gamma globulins. New Engl J Med 315, 341-7 (1986)

49. S. Nonoyama: Immunological abnormalities and endothelial cell injury in Kawasaki disease. Acta Pediatr Jpn 33, 752-5 (1991)

50. E.S. Lekora, L. Joffe \& M.P. Golde: Antigenic recognition of intravenous gamma globulin of selected bacteria isolated from throats of patients with Kawasaki syndrome. Pediatr Infect Dis J 9, 6203 (1990)

51. E. Arsura: Experience with intravenous immunoglobulin in myasthenia gravis. Clin Immunol Immunopathol 53, S 170-9 (1989)

52. P. Gajdos: Intravenous immunoglobulin in myasthenia gravis. Clin Exp Immunol 97 (Suppl 1), 49-51 (1994)

53. P.A. van Doorn, M. Vermeulen, A. Brand, P.G.H. Mulder \& H.F.M. Busch: Intravenous immunoglobulin treatment in patients with chronic inflammatory demyelinating polyneuropathy. Clinical and laboratory characteristics associated with improvement. Arch Neurol 48,217-220 (1991)

54. C. Coulam, A. Peters, J. Mc Intyre \& W. Faulk: The use of IVIG for the treatment of recurrent spontaneous abortion. In: Immunotherapy with intravenous immunoglobulins (ed. P. Imbach). Academic Press, London, 1991, 395-400
55. O. Heine and G. Mueller-Eckhardt: Intravenous immune globulin in recurrent abortion. Clin Exp Immunol 97 (Suppl 1), 39-42 (1994)

56. A.K. Gupta, N.H. Shear \& D.N. Sauder: Efficacy of human intravenous immune globulin in pyoderma gangrenosum. J Am Acad Dermatol 32, 140-2 (1995)

57. C. Mohr, C. Sunderkotter, A. Hilderbrand, K. Biel, A. Rutter, G.H. Rutter, T.A. Leuger \& G. Kolde: Successful treatment of epidermolysis bullosa acquisita using intravenous immunoglobulins. $\mathrm{Br} J$ Dermatol 132, 824-6 (1885)

58. A.K. Sharma \& M.K. Pangburn: Biologically active recombinant factor $\mathrm{H}$ : synthesis and secretion by baculovirus system. Gene 143, 301-2 (1994)

59. R.G. Trapp, M. Fletcher, J. Forristall \& C.D. West: $\mathrm{C} 4$ binding protein deficiency in a patient with atypical Behcet's disease. J Rheumatol 14, 135-8 (1987)

60. A.J. Bonnin, H.J. Zeitz \& A. Gewurz: Complement factor I deficiency with recurrent aseptic meningitis. Arch Intern Med 153, 1380-3 (1993)

61. J.B. Ziegler, C.A. Alper, R.S. Rosen, P.J. Lachmann \& L. Sherington: Restoration by purified $\mathrm{C} 3 \mathrm{~b}$ inactivator of complement mediated function in vivo in a patient with $\mathrm{C} 3 \mathrm{~b}$ inactivator deficiency. $J$ Clin Invest 55: 668-72 (1975)

62. M.E. Medof, E.I. Walter, J.L. Rutgers, D.M. Knowles \& V. Nussenzeweig V: Identification of the complement decay accelerating factor (DAF) on epithelium and glandular cells and in body fluids. $J$ Exp Med 165, 848-64 (1987)

63. T. Hara, S. Kuriyama, H. Kiyohara, M. Nagase, M. Matsumoto \& T. Saya: Soluble forms of membrane cofactor protein (CD 46, MCP) are present in plasma, tears and seminal fluid in normal subjects. Clin Exp Immunol 89: 490-4 (1992)

64. S. Yoon \& D.T. Fearon: Characterization of a soluble form of the $\mathrm{C} 3 \mathrm{~b} / \mathrm{C} 4 \mathrm{~b}$ receptor $(\mathrm{CR} 1)$ in human plasma. J Immunol 134, 3332-8 (1985)

65. P. Moran, H. Beasley, A. Gorrell, E. Martin, P. Gribling, H. Fuchs, N. Gillet, L.E. Burton \& I.W. Caras: Human recombinant soluble decay accelerating factor inhibits complement activation in vitro and in vivo. J Immunol 149, 1736-43 (1992)

66. D.M. Lubin \& K.E Coyne: Phospholipid anchored and transmembrane versions of either decayaccelerating factor or membrane cofactor protein show equal efficiency in protection from complement mediated cell damage. J Exp Med 174, 35-44 (1991) 
67. G.C. Yeh, H.C. Marsh Jr, G.R. Carson, L. Berman, M.F. Concino, S.M. Scesney, R.E. Kuestner, R. Skibbens, K.A. Donahue \& S.H. Ip: Recombinant soluble human complement receptor type 1 inhibits inflammation in the reverse passive Arthus reaction in rats. J Immunol 146, 250-6 (1991)

68. K.R. Kalli, P. Hsu \& D.T. Fearon: Therapeutic uses of recombinant complement proteins. Springer Semin Immunopathol 15, 417-31 (1994)

69. J.L. Platt: A perspective on xenograft rejection and accommodation. Immunol Rev 141, 127-49 (1994).

70. W.M. Baldwin 3rd, S.K. Pruit, R.B. Brauer, M.R. Daha \& F. Sanfilippo: Complement in organ transplantation. Transplantation 59, 797-808 (1995)

71. A.P. Dalmasso: The complement system in xenotransplantation. Immunopharmacology 24, 14960 (1992)

72. D.H. Sachs: The pig as a potential xenograft donor. Veterin Immunol Immunopathol 43, 185-91 (1994)

73. E. Cozzi, G.A. Langford, L. Wright, A. Tucker, M. Yannoutsos, A. Richards, A. Rosengards, K. Elsome, R. Lancaster \& D.J.G. White: Comparative analysis of human DAF expression in the tissues of transgenic pigs and man. Transpl Proceed 27, 319-20 (1995)

74. G. Rosengard, N. Cary, J. Horseley, C. Belcher, G. Lagford, E. Cozzi, J. Wallwork, D.J.G. White: Endothelial expression of human decay accelerating factor in transgenic pig tissue. A potential approach for human complement inactivation in discordant xenografts. Transpl Proc 27, 326-27 (1995)

75. F.D. Moore Jr: Therapeutic regulation of the complement system in acute injury states. $A d v$ Immunol 56, 267-99 (1994)

76. H.J. Weisman, T. Bartow, M.K. Leppo, H.C. Marsh Jr, G,R. Carson, M.F. Concino, M.P. Boyle, K.H. Roux, M.L. Wiesfeldt \& D.T. Fearon: Soluble human complement receptor type 1 : in vivo inhibitor of complement suppresses post-ischemic myocardial inflammation and necrosis. Science 249, 146-51 (1990)

77. J. Hill, T.H. Lindsay, F. Ortiz, C.G. Yeh, H.B. Hechtman, F.D. Moore Jr: Soluble complement receptor type 1 ameliorates the local and remote organ injury after intestinal ischemia-reperfusion in the rat. J Immunol 149, 1723-8 (1992)
78. M. Pemberton, G. Anderson, V. Vetvicka, D.E. Justus \& G.D. Ross. Microvascular effects of complement blockade with soluble recombinant CR1 on ischemia and reperfusion injury of skeletal muscle. $J$ Immunol 150, 5104-13 (1993)

79. T. Morisaki, T. Goya, H. Toh, K. Nishihara \& Toisu M: The anti-Mac-1 monoclonal antibody inhibits neutrophil sequestration in lung and liver in a septic murine model. Clin Immunol Immunopathol 61, 365-75 (1991)

80. P. Grob, M. Holch, W. Fierz, W. Glinz \& S. Geroulanos: Immunodeficiency after major trauma and selective surgery. Pediatr Infect Dis J 7, S37-42 (1988)

81. M.S. Mulligan, C.G. Yeh, A.R. Rudolph \& P.A. Ward: Protective effects of soluble CR1 in complement and neutrophil-mediated injury. $J$ Immunol 148, 1479-85 (1992)

82. S.K. Pruitt, A.D. Kirk, R.R. Bollinger, H.C. Marsh, B.H. Collins, J.L. Levin, J.R. Mault, J.S. Heinle, S. Ibrahim, A.R. Rudolph, W.M. Baldwin \& F. Sanfilippo: The effect of soluble complement receptor type 1 on hyperacute rejection of porcine xenografts. Transplantation 57, 363-70 (1994)

83. S.K. Pruitt \& R.R. Bollinger: The effect of soluble complement receptor type 1 on hyperacute allograft rejection. J Surg Res 50, 350-5 (1991)

84. W. Xia, D.T. Fearon, F.D. Moore Jr, F.J. Schoen, F. Ortiz \& RL Kirkman: Prolongation of guinea pig cardiac xenograft survival in rats by soluble human complement receptor type 1. Trans Proc 24: 479-80 (1992)

85. B.P. Morgan: Complement regulatory molecules: application to therapy and transplantation. Immunology Today 16, 257-9 (1995)

86. U.S. Ryan: Blockade of complement using soluble complement receptors. Cambridge Healthcare Institute's Conference on Prevention of Reperfusion Injury. Omni Royal Orleans, New Orleans, Louisiana, USA. February 20-21, (1995)

87. W.L. Fodor, B.L. Williams, L.A. Matis, J.A. Madri, S.A. Rollins, J.W. Knight, W. Velander \& S.P. Squinto: Expression of functional complement inhibitor in a transgenic pig as a model for prevention of xenogeneic hyperacute organ rejection. Proc Natl Acad Sciences USA. 91, 11153-7 (1994) 